\title{
Da dimensão sociocomunicativa à arquitetura textual na abordagem didática do gênero resenha acadêmica
}

\author{
Regina Celi Mendes Pereira ${ }^{1}$ \\ Programa de Pós-Graduação em Linguística, Universidade Federal da Paraíba, João Pessoa, PB, Brasil \\ Evandro Gonçalves Leite ${ }^{2}$ \\ Programa de Pós-Graduação em Letras, Universidade do Estado do Rio Grande do Norte, Pau dos Ferros, RN,
}

Resumo: O objetivo deste trabalho é socializar uma experiência didática de produção do gênero resenha acadêmica com alunos de graduação em Letras, destacando as capacidades e operações de linguagem postas em funcionamento pelos alunos durante atividades de escrita e reescrita. Os aportes teórico-metodológicos do Interacionismo Sociodiscursivo associados à abordagem dos Letramentos Acadêmicos conduzem nossas reflexões sobre aspectos sociocomunicativos e textuais-discursivos da resenha e do processo de didatização empreendido. Os dados foram gerados em pesquisa-ação de caráter qualitativo-interpretativista, mediante a condução de atividades com o gênero que culminaram na produção de resenhas pelos alunos. Na avaliação dos textos, observamos que as mudanças frente à apropriação do gênero ocorreram com mais intensidade no nível das capacidades discursivas e linguístico-discursivas, que, na materialidade do texto, revelam questões relacionadas a papéis sociais e identidades que se constroem na vivência com a escrita acadêmica e os conhecimentos de determinado campo disciplinar.

Palavras-chave: Letramentos Acadêmicos; Resenha; Capacidades de linguagem; Abordagem Didática.

Title: From the sociocommunicative dimension to textual architecture in the didactic approach of academic book review genre

Abstract: The purpose of this paper is to socialize a didactic experience of production of the academic book review genre with students of graduation in Letters, highlighting the abilities and language operations put into operation by the students during activities of writing and rewriting. The theoretical-methodological contributions of Sociodiscursive Interactionism associated to the approach of the Academic Literacies lead our reflections on socio-communicative and textual-discursive aspects of the academic book review and the process of didatization accomplished. The data were generated in qualitativeinterpretative action research, through the conduction of activities with the genre that culminated in the production of book reviews by the students. In the evaluation of the

\footnotetext{
${ }^{1}$ Doutora em Letras (Universidade Federal de Pernambuco), Universidade Federal da Paraíba. Orcid: https://orcid.org/0000-0002-5538-035X

E-mail: reginacmps@gmail.com

${ }^{2}$ Doutorando em Letras (Universidade do Estado do Rio Grande do Norte), Instituto Federal de Educação, Ciência e Tecnologia do Rio Grande do Norte. Orcid: https://orcid.org/0000-0002-42407904

E-mail: evandrogleite@yahoo.com.br
} 
texts, we observed that the changes towards gender appropriation occurred more intensively at the level of discursive and linguistic-discursive capacities, which, in the materiality of the text, reveal issues related to social roles and identities that are built in the experience with academic writing and the knowledge of a certain disciplinary field.

Keywords: Academic Literacies; Book review; Language capacities; Didactic approach.

\section{Introdução}

Os estudos de textos da esfera acadêmica têm focalizado diversos aspectos: descrição de suas características, construção de modelos didáticos e didatização de gêneros que circulam nesse ambiente. Nesse contexto se inserem as investigações do Ateliê de Textos Acadêmicos (ATA) - Processo no 23038.007066/2011-60 -, projeto que objetiva analisar as especificidades dos parâmetros de produção e da arquitetura textual (BRONCKART, 1999, 2006) de gêneros acadêmicos em diferentes áreas de conhecimento e desenvolver processos didáticos para a escrita acadêmica em contexto universitário. No âmbito da didatização de gêneros acadêmicos, o ATA tem realizado oficinas com a comunidade acadêmica e ações em sala de aula, bem como analisado seus resultados.

Uma dessas experiências em sala de aula diz respeito a uma proposta de ensino desenvolvida com o gênero resenha acadêmica, realizada na Licenciatura em Letras Português da Universidade Federal da Paraíba, na disciplina Leitura e Produção de Textos II, ministrada para alunos do 2 o período do curso. O objetivo deste trabalho, em consonância com essas ações, é socializar os resultados dessa experiência didática, procurando, prioritariamente, analisar como os alunos, mediante a intervenção formativa do professor, constroem e mobilizam diferentes conhecimentos (capacidades e operações de linguagem) necessários à produção do gênero. Com isso, poderemos investigar não somente como os alunos se apropriam de características e modelos de gêneros textuais, mas também como se relacionam com a escrita acadêmica, na compreensão de papéis sociais e convenções que a caracterizam.

Muitos trabalhos têm abordado o gênero resenha, sob diferentes enfoques: em um contexto mais descritivo, por exemplo, buscam descrever suas características (CUNHA, 2014; MACHADO, 1996; RUIZ; FARIA, 2012); já em um viés de didatização, relatam a elaboração e a implementação de propostas didáticas (BALTAR, 2006; LOUSADA; SANTOS; BARIONI, 2016), bem como analisam os resultados (textos empíricos) delas advindos (ARAÚJO; BARROS; SILVA, 2015; BRAGA; SENEM, 2017; RODRIGUES, 2013). Nosso estudo, de certa forma, une essas duas perspectivas de didatização, ao relatar uma experiência didática com o gênero e analisar suas implicações mediante os produtos empíricos delas resultantes: as resenhas produzidas pelos alunos.

Assim, tomamos por base as contribuições teórico-metodológicas do Interacionismo Sociodiscursivo (ISD), para embasar a construção da intervenção didática e descrever as 
capacidades e operações de linguagem postas em funcionamento na produção do gênero resenha; e dos Estudos de Letramento, particularmente a abordagem dos Letramentos Acadêmicos, no sentido de compreender a escrita como prática social situada, no contexto de disciplinas. Quanto ao processo de geração dos dados, recorremos à pesquisa-ação, já que elaboramos e aplicamos uma proposta de intervenção didática em nosso campo de atuação docente, na condição de ministrante da disciplina Leitura e Produção de Textos II. Nesse processo, procuramos registrar ações que empreendemos e coletamos textos dos alunos, que constituem nosso material de análise, a ser submetido a um tratamento qualitativo-interpretativista.

Nosso artigo encontra-se estruturado da seguinte forma: de início, apresentamos nossos aportes teórico-metodológicos, respectivamente dos Estudos de Letramento e do Interacionismo Sociodiscursivo; em seguida, relatamos a proposta de intervenção didática; posteriormente, procedemos à análise das resenhas, como produtos empíricos desse processo; por fim, procuramos tecer algumas considerações finais sobre os resultados que obtivemos.

\section{Dos letramentos aos letramentos acadêmicos: alguns apontamentos}

As reflexões sobre letramento nas quais nos respaldamos advêm das contribuições de Street (1984), que têm influenciado outros estudos - como Barton e Hamilton (1998, 2000), Gee (2008), Street $(1993,2014)$ e, no Brasil, Kleiman (1995), Kleiman e Assis (2016), Soares (2006, 2009) e tantos outros -, numa perspectiva teórica que se convencionou chamar de Novos Estudos de Letramento ou, simplesmente, Estudos de Letramento.

Segundo essa concepção, deve-se compreender o letramento para além de pura técnica independente do contexto social e com consequências sociais e cognitivas intrínsecas, "autônomas". Pelo contrário, defende-se que a leitura e a escrita sejam vistas e estudadas como práticas sociais ideológicas, visto que relacionadas a aspectos culturais, relações de poder e, portanto, inseridas na vida social. Nas palavras de Street (1984, p. 97), "[...] ele [o letramento] é um processo social, no qual determinadas tecnologias socialmente construídas são usadas dentro de quadros institucionais específicos para propósitos sociais específicos [... $]^{\prime 3}$. Nesse caso, os usos e as funções da escrita baseiam-se em valores, normas, percepções e interesses particulares de indivíduos, grupos ou instituições, de modo que as convenções e habilidades letradas requeridas, desenvolvidas ou empregadas nesses contextos são específicas, porque relacionadas a situações e finalidades particulares, embora possam ser adaptadas a outros contextos.

\footnotetext{
${ }^{3}$ No original: "[...] it [literacy] is a social process, in which particular socially constructed technologies are used within particular institutional frameworks for specific social purposes. [...]" (STREET, 1984, p. 97).
} 
Com base nessa compreensão, Barton e Hamilton (2000) definem algumas características (ou facetas) do letramento: é entendido como um conjunto de práticas, depreendidas a partir de eventos mediados por textos; varia de acordo com os domínios da vida, de modo que podemos falar de diferentes letramentos, haja vista que cada domínio possui atividades particulares que obedecem a certas regularidades, configurações e relações de poder; está associado a interesses e motivações, de acordo com seus usos (objetivos e práticas culturais); é historicamente situado e, por isso, dinâmico, guiado por permanências e mudanças; é apreendido em situações informais e formais de aprendizagem, a partir dos significados e dos conhecimentos que se constroem, pelos interactantes, sobre seus usos.

Assim sendo, como as práticas de letramento variam de acordo com o contexto, não é possível falar de um letramento que seja autônomo e cujas consequências sociais e individuais the sejam intrínsecas, mas de diferentes tipos, de acordo com os diferentes domínios de vida. Um deles é o acadêmico, que congrega gêneros de texto da esfera acadêmica e cujas práticas de leitura e de escrita têm sido objeto de estudo de uma abordagem teórica denominada de Letramentos Acadêmicos, assim conceituada por seus idealizadores:

Aprender no ensino superior envolve a adaptação a novas formas de conhecimento: novas formas de compreensão, interpretação e organização do conhecimento. Práticas de letramento acadêmico - leitura e escrita dentro de disciplinas - constituem processos centrais através dos quais os alunos aprendem novos assuntos e desenvolvem seus conhecimentos sobre novas áreas de estudo. Uma abordagem prática para o letramento leva em conta o componente cultural e contextual das práticas de escrita e leitura, e isso, por sua vez, tem implicações importantes para a compreensão da aprendizagem dos alunos (LEA; STREET, 1998, p. 157). ${ }^{4}$

Os autores compreendem a escrita na esfera acadêmica como portadora de peculiaridades não apenas quanto ao conteúdo nela expresso, mas também quanto a questões institucionais e epistemológicas, a gêneros de texto, a distintas formas de produzir e organizar o conhecimento, aos papéis sociais dos interactantes, enfim, a certas convenções de uso e funções próprias da escrita no âmbito de atividades também singulares nesse ambiente. Além disso, levam em conta as diferenças entre os diversos contextos disciplinares

\footnotetext{
${ }^{4}$ No original: "Learning in higher education involves adapting to new ways of knowing: new ways of understanding, interpreting and organizing knowledge. Academic literacy practices - reading and writing within disciplines - constitute central processes through which students learn new subjects and develop their knowledge about new areas of study. A practices approach to literacy takes account of the cultural and contextual component of writing and reading practices, and this in turn has important implications for an understanding of student learning" (LEA; STREET, 1998, p. 157).
} 
(daí a utilização do termo "letramentos acadêmicos", no plural), pois cada disciplina, de forma situada, tem seus valores, convenções, epistemologias, identidades e relações de poder, que (se) constituem ( $n$ )as mais variadas e multiformes práticas letradas que nela ocorrem.

Assim, a abordagem dos Letramentos Acadêmicos, alicerçada nos trabalhos de Lea e Street $(1998,2000,2014)$ e Lea $(2004,2005)$, rejeita a ideia de que, no contexto acadêmico, a compreensão, o estudo e o ensino da escrita se restrinjam a habilidades técnicas, normalmente circunscritas a elementos de natureza gramatical que, uma vez adquiridas, podem ser transferíveis a todas as situações de uso da escrita na academia, independentemente das especificidades das disciplinas. Também considera insuficiente a socialização acadêmica, entendida como estudo e ensino de convenções de uma área do conhecimento, geralmente relacionadas a modelos de gêneros, embora já haja, nesse caso, o entendimento da escrita como prática situada.

De modo a ampliar a compreensão do funcionamento e do ensino da leitura e da escrita no contexto acadêmico, essa corrente advoga que é preciso levar em consideração não apenas habilidades técnicas e convenções de modelos textuais de uma área, mas também, e principalmente, questões epistemológicas, identitárias e relações de poder que envolvem todo esse processo. Assim, as instituições definem convenções e certas práticas de escrita, que guiam a percepção de estudantes e professores e moldam os textos que eles experienciam. De igual modo, esses textos são as manifestações empíricas e observáveis de tais representações e, ao mesmo tempo, os instrumentos que permitem a construção e a propagação dos modos de funcionamento das disciplinas. Cria-se, assim, um imbricamento entre textos e práticas, que são indissociáveis na investigação da escrita e do seu ensino nos diferentes contextos de uso, entre eles o acadêmico.

No que tange especificamente à dimensão didática, Street (2010a, 2010b) destaca a necessidade de focalizar as implicações pedagógicas da abordagem dos Letramentos Acadêmicos, relacionando-os com estudos de gêneros no âmbito de disciplinas, a fim de abordá-los num sentido mais amplo, considerando valores, relações de poder e identidades que emergem nas práticas das quais eles fazem parte. Nesse sentido, o autor oferece alguns subsídios para o ensino da leitura e da escrita no contexto acadêmico, a partir de uma experiência com o artigo científico.

Assim, defende-se que, no ensino da leitura e da escrita no ambiente acadêmico, considerem-se, evidentemente, questões disciplinares e institucionais que as envolvem e, especialmente, as formas como os estudantes interpretam e experienciam tais práticas (LEA, 2004), de modo a oferecer instruções e feedbacks que promovam uma interação mais dialógica e efetiva entre os interactantes e destes com os objetos de ensino e de conhecimento, levando em conta as necessidades de aprendizagem e os conflitos que pode haver nesse processo (LEA; STREET, 2000; LILLIS, 1999, 2003; TURNER, 1999). Além disso, elenca critérios os mais diversos, como contexto de produção (gênero, audiência, finalidade), 
estrutura, marcas de textualização, elementos enunciativos (voz do autor, ponto de vista) e linguísticos que muitas vezes podem ficar escondidos ("ocultos") no ensino dos gêneros acadêmicos (STREET, 2010a, 2010b).

O ponto nodal dessa proposta, então, é que se explicitem claramente aos alunos os elementos constitutivos dos gêneros - imersos nas práticas letradas -, a serem levados em consideração pelos professores, orientadores ou avaliadores no ensino da escrita, do planejamento à reescrita. Ao mesmo tempo, que se atente para os significados que os alunos constroem para tais práticas e textos, a fim de que se possa melhor intervir no processo de ensino. Assim, espera-se que os alunos, interagindo efetivamente com membros mais experientes, em práticas significativas de uso da escrita, possam construir significados e conhecimentos sobre elas.

\section{Definindo uma abordagem de gênero: aportes do Interacionismo Sociodiscursivo}

Diante da necessidade de aliar o ensino das práticas de escrita, mais especificamente no ambiente acadêmico, a uma abordagem de gêneros textuais, evocamos as reflexões do Interacionismo Sociodiscursivo (ISD), que pretende estudar os textos e seu funcionamento, inclusive nas práticas escolares, como ações de linguagem situadas no quadro de atividades sociais (BRONCKART, 1999, 2006). Segundo essa perspectiva, os gêneros de texto são instrumentos de ação, na medida em que acompanham, organizam e possibilitam o agir humano em diferentes esferas e atividades sociais, além de serem responsáveis pelo desenvolvimento de conhecimentos nos seres humanos (SCHNEUWLY; DOLZ, 2004).

Assim, a realização de uma ação de linguagem (leitura, escuta ou produção de um texto pertencente a um determinado gênero numa situação de interação) requer a mobilização, por parte de um agente, de um conjunto de conhecimentos, tratados como capacidades de linguagem (DOLZ, SCHNEUWLY, 2004) - de ação, discursivas e linguísticodiscursivas -, que congregam uma série de operações de linguagem (BRONCKART, 1999, 2006), num modelo de descrição e de análise descendente, que apresentaremos relacionando a características do gênero resenha acadêmica ${ }^{5}$.

As capacidades de ação aludem à mobilização de conhecimentos (representações sociais interiorizadas) relativos às características do contexto físico e sociossubjetivo (emissor e sua posição social, receptor e sua posição social, tempo e lugar físico e social e objetivo da interação), assim como do referente (conteúdo temático), que delineiam a ação de linguagem, determinam a escolha e a adaptação do modelo de gênero mais adequado a tais parâmetros e às demais capacidades que serão mobilizadas na construção do texto empírico.

Quanto a esse aspecto, a resenha acadêmica é um gênero que circula na esfera

\footnotetext{
${ }^{5}$ Denominamos resenha acadêmica aquela que circula no ambiente acadêmico, para diferenciá-la da resenha jornalística, que circula em outro ambiente.
} 
acadêmica, é geralmente publicada em periódicos especializados e tem a função de avaliar/apreciar um objeto cultural ou produção intelectual de uma área do conhecimento (MOTTA-ROTH; HENDGES, 2010), geralmente um livro, o que coloca a criticidade como uma de suas características principais (RODRIGUES, 2013). O autor assume a condição de especialista e fornece opinião crítica sobre determinado assunto a um leitor que procura informações e indicações sobre uma obra. O conteúdo temático normalmente versa sobre informações e comentários sobre o objeto resenhado.

As capacidades discursivas referem-se à utilização dos modelos discursivos, a comporem a infraestrutura textual, já na dimensão empírica do texto, a partir de três operações. Uma delas diz respeito aos tipos de discurso e sua articulação ${ }^{6}$, que semiotizam mundos discursivos criados a partir de duas operações - relação de conjunção (expor) ou de disjunção (narrar) entre as coordenadas do conteúdo temático e as coordenadas do mundo ordinário em que ocorre a ação de linguagem e relação de implicação ou de autonomia entre as instâncias de agentividade mobilizadas no texto (como personagens, grupos, instituições) e sua inscrição espaço-temporal e os parâmetros físicos da ação de linguagem -, cujo cruzamento forma mundos discursivos e seus respectivos tipos linguísticos: expor implicado (discurso interativo), expor autônomo (discurso teórico), narrar implicado (relato interativo) e narrar autônomo (narração). Outra refere-se a conhecimentos sobre sequências textuais (narrativa, descritiva, argumentativa, explicativa, injuntiva e dialogal) ou outras formas de planificação (scripts e esquematização) utilizadas na composição do texto. Uma terceira concerne ao plano de texto, que é uma espécie de resumo da organização do conteúdo temático.

$\mathrm{Na}$ resenha, predomina o discurso teórico, conforme Lousada, Santos e Barioni (2016). Em relação às sequências, destaca-se a argumentativa, dada a função social do gênero, mas observa-se uma heterogeneidade tipológica (RUIZ; FARIA, 2012), com presença das sequências explicativa e descritiva. Já o plano geral é composto, segundo Motta-Roth e Hendges (2010), pelas seguintes etapas (ou movimentos retóricos): apresentar a obra, descrevê-la, avaliá-la e recomendá-la ou não.

As capacidades linguístico-discursivas dizem respeito ao estabelecimento da coerência temática e pragmática do texto, congregando operações na dimensão dos mecanismos de textualização (coesão nominal e conexão), dos mecanismos enunciativos (posicionamento enunciativo, gerenciamento de vozes e modalizações) e da microestrutura linguística (construção de enunciados, orações e períodos e escolha de itens lexicais).

Os aspectos de textualização mais característicos do gênero compõem-se de cadeias referenciais que remetem ao autor da obra, à obra e ao seu conteúdo (MACHADO, 2005) e de conectores lógicos para articular as partes do texto (LOUSADA; SANTOS; BARIONI, 2016).

\footnotetext{
${ }^{6}$ Aos tipos de discurso foi integrada a operação de estabelecimento da coesão verbal, conforme Cavalcante (2015), referente à organização e à hierarquização de estados, acontecimentos e ações do texto.
} 
Em relação aos mecanismos enunciativos, pode-se observar a presença de várias vozes autor da resenha, autor da obra resenhada e, eventualmente, outros da literatura especializada -, demonstrando o caráter intertextual do gênero (RUIZ; FARIA, 2012). Além disso, são utilizadas expressões de caráter avaliativo e modalizador, como verbos, advérbios e adjetivos, para marcar a apreciação do objeto resenhado (MACHADO, 2005).

Essas capacidades, com suas respectivas operações, podem ser vistas como aptidões, frutos de aprendizagens sociais, que devem ser apreendidas e mobilizadas pelos agentes quando da realização de uma ação de linguagem. Desse modo, nas situações de ensino da língua, tais capacidades, relacionadas às características de cada tipo de enunciado (como fizemos em relação à resenha acadêmica), definem o que Schneuwly e Dolz (2004, p. 75) denominam de dimensões ensináveis dos gêneros: "[...] 1) os conteúdos e os conhecimentos que se tornam dizíveis por meio dele; 2) os elementos das estruturas comunicativas e semióticas partilhadas pelos textos reconhecidos como pertencentes ao gênero; 3) as configurações específicas de unidades de linguagem [...]".

Essas dimensões ensináveis podem ser abordadas em sequências didáticas, que são, nas palavras de Dolz, Noverraz e Schneuwly (2004, p. 97), "[...] um conjunto de atividades escolares organizadas, de maneira sistemática, em torno de um gênero textual oral ou escrito", com o objetivo de ajudar o aluno a dominá-lo melhor. Elas organizam-se em diversas fases (apresentação da situação, produção inicial, módulos e produção final), linearmente distribuídas, como podemos visualizar na figura a seguir:

Figura 1 - Esquema do modelo de sequência didática

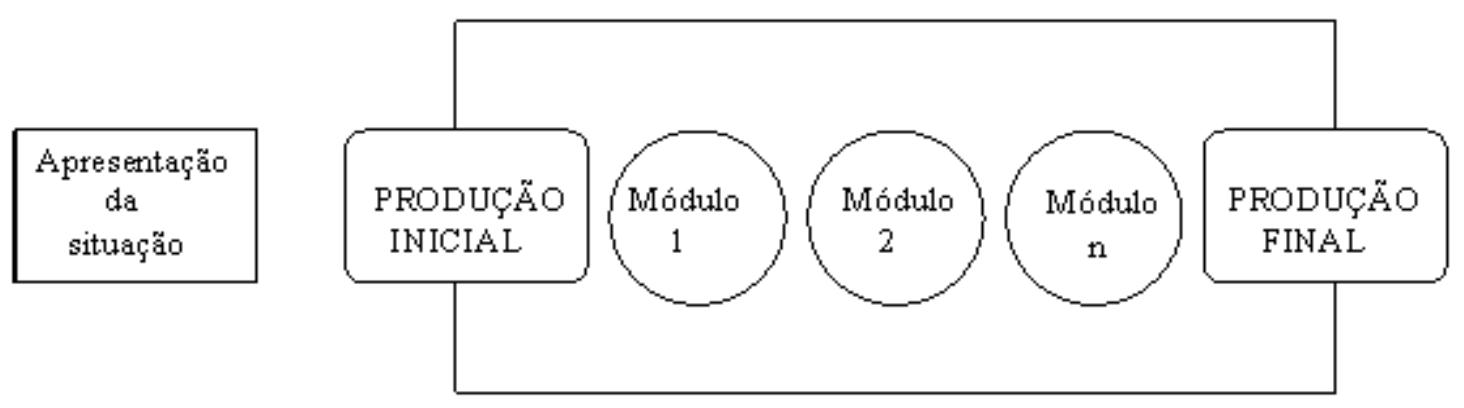

Fonte: Dolz, Noverraz e Schneuwly (2004, p. 98)

A primeira corresponde à apresentação, de maneira detalhada, do projeto de comunicação oral ou escrito que será desenvolvido e à preparação dos conteúdos dos textos que serão produzidos. A segunda, ao primeiro contato com o gênero, que permite ao professor perceber as necessidades de aprendizagem dos alunos, a partir das quais são realizadas a modulação e a adaptação da sequência. A terceira, às tarefas e exercícios, nos quais o gênero é decomposto em diferentes capacidades de linguagem, cada uma delas transformada em objeto de ensino. A quarta, à fase final: uma nova produção. 
Com base nesse modelo, Swiderski e Costa-Hübes (2009) apresentam uma adaptação, adicionando uma fase de reconhecimento do gênero, entre a apresentação da situação e a produção inicial. Consiste num módulo de atividades e exercícios de leitura, pesquisa e análise linguística a contemplar a funcionalidade e elementos temáticos, composicionais e estilísticos do gênero em estudo, a fim de que o aluno, antes de chegar à atividade de produção, possa ter contato com variadas características (sociocomunicativas, discursivas, textuais, enunciativas e linguísticas) dos textos do gênero em estudo.

Assim, as operações e capacidades de linguagem podem ser amplamente abordadas nas atividades de leitura e de escrita de textos de diferentes gêneros, dentre eles a resenha acadêmica. Como os textos não existem isolados das práticas, desenvolver capacidades de linguagem e conhecimentos sobre seu funcionamento nas atividades de que eles fazem parte significa ensinar formas de participação social e de inserção em espaços de produção e de socialização de conhecimento científico, no caso do ambiente acadêmico.

\section{Relato da proposta didática}

A proposta didática com o gênero resenha acadêmica foi desenvolvida numa turma do curso de Licenciatura em Letras Português, no período noturno 2018.1, da Universidade Federal da Paraíba, Campus I, João Pessoa, na disciplina Leitura e Produção de Textos II, ofertada no segundo semestre do curso. Havia na turma 29 alunos matriculados, mas efetivamente cursaram 20.

A ementa da disciplina contempla as concepções de escrita, o papel da escrita e o lugar do escritor na sociedade, situando os gêneros textuais e as práticas de letramento em dois contextos definidos: o escolar e o acadêmico, de modo relacionado. Seguem-se a essas reflexões teórico-conceituais, que incluem exposição sobre os elementos constitutivos da textualidade, atividades práticas e embasamento didático-pedagógico para a produção de diferentes gêneros específicos a essas esferas. Nesse sentido, são trabalhados o resumo, o artigo, o esquema e a resenha. No período 2018.1, elegemos o resumo e a resenha como foco das atividades de produção de texto e de avaliação formativa. Além dessas atividades, os alunos foram avaliados conceitual e analiticamente com um exercício escrito e elaboraram uma abordagem didática para o trabalho com a produção de textos voltada para o contexto de educação básica.

Entendemos, assim, que o propósito principal das atividades que realizamos com o gênero resenha, no contexto da formação universitária de alunos iniciantes no curso, foi, na esteira do que propõe Navarro (2014), proporcionar aos que estão em formação inicial um maior protagonismo na elaboração de textos, ainda que esses não atingissem todos os requisitos dos gêneros especializados. No caso específico da resenha, sabe-se que o resenhista, conforme já dissemos na seção anterior, é alguém especializado no interior de 
um determinado campo disciplinar, portador de uma autoridade cuja avaliação pode ser decisiva na validação de uma obra. Mesmo que essa não seja ainda a condição dos alunos em formação inicial, a vivência dessas práticas letradas permite-lhes desenvolver capacidades de leitura e escrita de modo mais pontual, sistemático e crítico, que lhes garantam conhecimentos sobre os gêneros, os valores, as convenções e certos conceitos de tal comunidade e, consequentemente, sobre modos de participação social em contextos de interação em que tais conhecimentos sejam necessários, configurando o que entendemos como práticas de letramento acadêmico.

Certamente, quando se elabora um plano didático, busca-se oferecer, a princípio, os elementos do contexto que forneçam a base de orientação para a escrita inicial do texto. Além disso, tem-se em vista abordar aspectos no plano discursivo e linguístico-discursivo implicados na ação de textualizar, que só se revelam nas operações de linguagem, tais como composicionalidade, seleção do vocabulário especializado, itens lexicais que melhor correspondam à intenção comunicativa, elementos de coesão, conexão e os de responsabilidade enunciativa, a exemplo das vozes e modalizações.

Assim, pautamo-nos no modelo de sequência didática e sua variação (DOLZ; NOVERRAZ; SCHNEUWLY, 2004; SWIDERSKI; COSTA-HÜBES, 2009), abordando as fases de apresentação da situação, o módulo de reconhecimento do gênero, a primeira produção, a correção dessa primeira produção e sua reescrita (esta considerada como produção final).

Os parâmetros do contexto sociossubjetivo da resenha, correspondente à apresentação da situação de produção, começaram a ser tematizados bem antes da elaboração efetiva do texto. No início do semestre, foi indicada aos alunos a leitura do livro "Resenha" (MACHADO; LOUSADA; ABREU-TARDELLI, 2004) e, devido ao seu caráter interativo e autoexplicativo, eles leram e fizeram as atividades sugeridas, mantendo, assim, os primeiros contatos com o gênero. Também foi lido e debatido em sala um capítulo que relata e analisa uma experiência didática com a resenha em uma turma de calouros de Licenciatura de Letras (PEREIRA; BASÍLIO, 2014). A leitura e a discussão provocaram interesse, pois geraram identificação dos alunos com o tema discutido e o contexto de análise, criando expectativa para a atividade futura de escrita.

No módulo de reconhecimento do gênero, foi apresentado aos alunos um esquema prototípico dos elementos composicionais e de natureza linguístico-discursiva que constituem a resenha, distribuído em 6 etapas: 1) contextualização do tema; 2) credenciais acadêmicas do autor; 3 ) apresentação panorâmica da obra; 4) pontos fortes e fracos da obra, com uma argumentação fundamentada; 5) intertextualidade (diálogo com outras obras que tratem do tema); e 6) indicação do leitor potencial. Obviamente, algumas dessas etapas não têm uma posição tão rígida nas resenhas publicadas - muitas vezes, a subversão das ordens depende muito da proficiência e da experiência do resenhista.

Ainda referente ao conhecimento sobre o gênero, em seus aspectos sociocomunicativos e linguístico-discursivos, organizamos uma sessão de debates em que os 
alunos apresentaram oralmente resenhas selecionadas de livros que já tivessem lido. Foi um momento produtivo em que puderam, por um lado, avaliar o caráter valorativo subjacente ao texto, o posicionamento do resenhista e até que ponto as impressões correspondiam às suas próprias percepções de leitura; e, por outro, interagir com convenções acadêmicas e formas de construir conhecimento na área por meio do gênero.

A sessão posterior de debates foi sobre o livro a ser resenhado, "A formação do professor de Português: que língua vamos ensinar?", de Paulo Coimbra Guedes (2006). A essa altura, boa parte da turma já havia lido o livro e foi possível conduzir uma discussão, destacando seus aspectos mais marcantes e os que mais chamaram atenção. Embora a publicação não seja recente, o tema discutido no livro continua atual e de especial interesse aos que pretendem ser professores de língua portuguesa, e não só a esses, mas a todos que se envolvem com a docência em geral, já que problematiza as diferentes concepções de professor e paradigmas pedagógicos ao longo das últimas décadas. Nesse ponto, destacamos a pertinência da obra a ser resenhada e de sua discussão também para a formação da identidade acadêmico-profissional dos alunos, no tocante à compreensão de conceitos e valores que permeiam a área.

Só depois da exposição oral e do debate sobre o livro é que os alunos redigiram a primeira versão da resenha. Tentamos, portanto, criar as condições de produção o mais próximo possível dos parâmetros que cercam a elaboração de uma resenha, mas, ainda assim, é uma situação didática, desenvolvida na dimensão do caráter "ensinável" do gênero, do gênero a aprender. De posse da primeira produção, realizamos um trabalho de correção dos textos, a fim de fornecer feedback aos alunos, considerando as maiores dificuldades e estranhamentos diante da elaboração de um novo gênero. Com base nessas orientações, eles reelaboraram suas resenhas. Assim, interessa-nos analisar como se deu o nível de apreensão do gênero com as orientações que antecederam a escrita e seu impacto na materialidade do texto, além do movimento entre a primeira e a segunda versão, motivado pelo feedback.

Para isso, selecionamos 3 resenhas do total das 19 que constituem nosso corpus. 0 critério de seleção se pautou em verificar aquelas que fossem mais representativas das dificuldades e necessidades de aprendizagem evidenciadas pelos alunos na primeira produção, bem como das aprendizagens adquiridas no curso do desenvolvimento da sequência didática, culminando na produção do texto final. As resenhas aparecem codificadas, a fim de manter em sigilo a identidade dos alunos, que nos autorizaram a utilizar os textos mediante a assinatura de termo de consentimento livre e esclarecido. 


\section{Um pouco de resenha: dos parâmetros de produção à materialidade textual}

A primeira produção evidenciou que muitos alunos não conseguiram se apropriar inteiramente de elementos constitutivos da resenha e da prática social em que ela está inserida. As ocorrências mais significativas situaram-se no modo como abordam o conteúdo temático e em como o aluno-resenhista gerencia as vozes, a sua e a do autor resenhado, incidindo, portanto, no desenvolvimento das capacidades discursivas e linguísticodiscursivas, mas que perpassam também as capacidades de ação, quando, por exemplo, o aluno deixa de inserir as indicações do leitor potencial da obra. Esses aspectos parecem remeter justamente à dificuldade dos alunos de assumirem o papel social de especialista que o gênero requer, pois não conseguem manejar os conceitos da área, tematizados no livro, nem os discutir sob seu ponto de vista ou de outrem.

Analisando os comentários que inserimos na avaliação dos textos, verificamos que as orientações para a reescrita contemplam todas as etapas, excetuando-se a do item 4, em que são apresentados os pontos fortes e fracos da obra, com uma argumentação fundamentada. Os demais comentários focalizam: 1) acréscimo de informações sobre as credenciais acadêmicas do autor do livro; 2) apresentação panorâmica da temática abordada no livro; 3) esclarecimento sobre alguns conceitos discutidos pelo autor da obra; 5) explicitação dos elementos linguístico-discursivos que introduzem e diferenciam as vozes presentes no texto; e 6) acréscimo da indicação do público leitor. Entendemos que os comentários dos itens 1 e 6 dizem respeito tanto aos aspectos sociocomunicativos da resenha, quanto aos referentes ao seu modo de planificação textual, alcançando, portanto, o desenvolvimento das capacidades de ação e discursivas; os dos itens 2 e 3 estão mais diretamente relacionados ao tratamento do conteúdo temático, logo, incidem na mobilização das capacidades discursivas; finalmente, os comentários do item 5 se situam na dimensão das capacidades linguístico-discursivas, as quais operam mais diretamente na gestão dos mecanismos textuais e enunciativos. Obviamente, a classificação das ocorrências de acordo com as capacidades não é linear e simétrica no processo de textualização. Uma solicitação referente a uma determinada ocorrência pode incidir sobre mais de uma capacidade de linguagem, e as alterações textuais feitas pelo aluno podem, inclusive, afetar uma capacidade não prevista na primeira leitura.

Apresentamos abaixo um trecho da resenha de J.L. (na primeira versão e na reescrita), a título de exemplificação das ocorrências mais frequentes localizadas nos textos e nos comentários referentes a eles. 
Figura 2 - Excerto de J.L. (primeira versão)

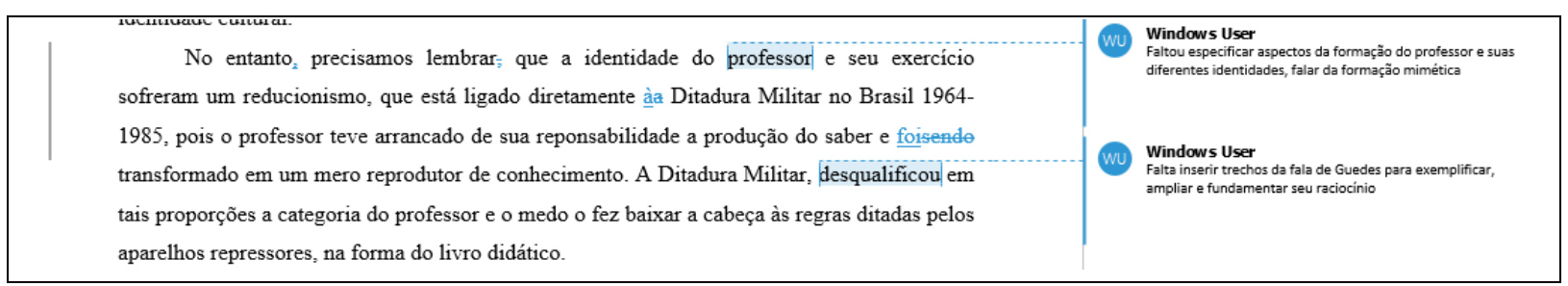

Fonte: Texto de J.L. / Arquivo pessoal dos autores

Quadro 1 - Excerto de J.L. (versão reescrita ${ }^{7}$ )

No entanto, precisamos lembrar que a identidade do professor (independentemente da sua língua materna) e seu exercício sofreram um reducionismo, que está ligado diretamente à Ditadura Militar no Brasil 1964-1985, pois o professor teve arrancado de sua responsabilidade a produção do saber e foi sendo transformado em um mero reprodutor de conhecimento. A Ditadura Militar começou com um projeto educacional que trouxe ao professor condições alarmantes de trabalho começando com o "arrocho salarial, causa e consequência da massificação que destruiu as condições matérias e intelectuais de trabalho do professor. A quantidade de horas passadas em sala de aula e quantidade de alunos em cada uma delas desqualificou" (GUEDES, p. 19) em tais proporções a categoria do professor e o medo o fez baixar a cabeça às regras ditadas pelos aparelhos repressores, na forma do livro didático.

Fonte: Texto de J.L. / Arquivo pessoal dos autores

A solicitação que diz respeito à ampliação do conteúdo temático, por exemplo, situase no contexto de produção do texto - portanto, na dimensão das capacidades de ação - e é ativada cognitivamente ainda no processo de leitura e compreensão do texto a ser resenhado, servindo como base de orientação a guiar as demais estratégias mobilizadas na materialização do texto empírico. Observações como essa sobre o conteúdo temático, por sua vez, refletem-se nas capacidades discursivas, quanto às partes da resenha, possibilitando ao aluno (re)construir os movimentos de resumir, citar e avaliar, bastante característicos do gênero. Por essa razão, enfatizamos o tempo empreendido na apresentação dos elementos do contexto de produção, objetivando criar as condições mais favoráveis à atividade linguageira, ainda que seja exclusivamente no nível das operações textuais-discursivas escritas que as representações e pré-construídos ganhem materialidade. Além disso, há outra observação na primeira versão que, no plano enunciativo, solicita do aluno que recorra à intertextualidade, para evidenciar com mais destaque a voz do autor da obra resenhada e, ao mesmo tempo, reforçar sua argumentação.

Em relação às mudanças feitas por J.L. na versão final de seu texto, houve certo avanço na ampliação do parágrafo em que foi solicitado acréscimo de informações sobre temas abordados na obra que está sendo resenhada. Esse acréscimo é feito principalmente mediante a incorporação de uma citação direta de Paulo Coimbra Guedes à sua resenha,

\footnotetext{
${ }^{7}$ As transcrições que fazemos são completamente fiéis aos textos originais.
} 
como forma de exercício dialógico e argumentativo na apresentação do resumo da obra. Ressaltemos, porém, que a expressão "independentemente de sua língua materna”, inserida na versão reescrita, não parece refletir as ideias de Guedes e, desse modo, fica deslocada em relação ao conteúdo temático ali abordado - acreditamos que o aluno confundiu o conceito de língua materna do professor com a língua que ele leciona. Além disso, o resenhista poderia ter empregado algum elemento de coesão para introduzir a citação direta de Guedes, demarcando melhor o diálogo entre as diferentes instâncias enunciativas do texto.

São esses dois aspectos abordados a partir dos exemplos da resenha de J.L. mobilização e organização do conteúdo temático e gerenciamento das vozes - que constituem as maiores dificuldades dos alunos e sobre as quais incide a maioria das observações na primeira versão e o trabalho de reescrita dos textos.

Observemos mais uma resenha, em suas duas versões:

Figura 3 - Excerto de G.E. (primeira versão)

O último elemento que o autor cita como contribuinte à crise tratada no livro são as
assessorias pedagógicas que, basicamente, cumprem o inverso daquilo que se propõem,
acrescentando fardos às costas do professor ao invés de lhe prestarem auxílio, isso porque
apontam inúmeras referências com as quais o professor pode equipar-se para renovar as suas
aulas e aderir ao "novo", contudo esquecem de que esse mesmo professor tem uma jornada de
trabalho extenuante, o que muitas vezes o impossibilita de atualizar-se, e ele precisaria de uma
formação literalmente continuada - não só de encontros! - para refletir precisamente sobre como
aperfeiçoar o seu fazer pedagógico.
Destarte, reprodução sistemática e irrefletida, despreparo, submissão aos programas

Fonte: Texto de G.E. / Arquivo pessoal dos autores

Quadro 2 - Excerto de G.E. (versão reescrita)

O último elemento que o autor cita como contribuinte à crise tratada no livro são as assessorias pedagógicas que, basicamente, cumprem o inverso daquilo que se propõem, acrescentando fardos às costas do professor ao invés de lhe prestarem auxílio, isso porque apontam inúmeras referências com as quais o professor pode equipar-se para renovar as suas aulas e aderir ao "novo", contudo esquecem de que esse mesmo professor tem uma jornada de trabalho extenuante, o que muitas vezes o impossibilita de atualizar-se, e conforme o que penso, ele precisaria de uma formação literalmente continuada - não só de encontros! - para refletir precisamente sobre como aperfeiçoar o seu fazer pedagógico.

Destarte, reprodução sistemática e irrefletida, despreparo, submissão aos programas educacionais, imposição dos conteúdos dos livros didáticos, dificuldade de produzir conhecimento 
científico e más condições de trabalho são marcas da crise de identidade vivenciada pelos professores em geral, inclusive o de português. Este, durante muito tempo, favoreceu a ideia de que só existe uma língua portuguesa: a prescrita pela gramática formal. O problema é que essa concepção apresenta grande teor elitista e discriminatório, o que, como o autor descreve, já foi detectado pelas massas, que não se enxergam falando a mesma língua que muitos políticos utilizam para persuadi-las.

Fonte: Texto de G.E. / Arquivo pessoal dos autores

No excerto que destacamos da primeira versão, as duas observações feitas na correção solicitam alterações quanto ao gerenciamento das vozes do resenhista e do autor da obra resenhada, a fim de que fiquem claras quais porções do conteúdo temático provêm de uma ou de outra. É importante estabelecer essa diferenciação, para que o leitor possa reconhecer os diferentes movimentos que constituem o plano de texto e o objetivo principal da resenha: resumir e avaliar. Na versão reescrita, o aluno insere duas orações: uma para marcar seu posicionamento ("conforme o que penso") e outra para indicar o pensamento de Guedes ("como o autor descreve"), demarcando as etapas textuais de avaliação e de resumo da obra. Entretanto, o conteúdo temático da primeira frase do segundo parágrafo do excerto não tem sua instância enunciativa (Guedes) estabelecida, o que nos possibilita fazer duas inferências: o aluno tem dificuldade em relação a essa operação, já que não foi capaz de identificar e sanar problemas da mesma natureza quando não apontados diretamente pelo professor; e/ou o aluno tende a compreender que todos os aspectos problemáticos do seu texto já haviam sido apontados pelo professor, de modo que se concentrou apenas neles ao proceder à reescrita.

Os exemplos seguintes também evidenciam o entrelaçamento entre as capacidades e os níveis de modificação na planificação do texto.

Figura 4 - Excerto de G.S. (primeira versão)

Fala sobre as identidades históricas atribuídas ao professor a primeira como um
sábio, detentor de todo o saber, num momento no qual a educação era dominada pelo
clero (jesuítas), e prezava-se pela rigidez e pela reprodução, o apego ao dogma e àa
autoridade. Fica evidente a desatualização do professor, todo o saber para eles estava
pronto e acabado, o professor não ia além dos livros, não podia ir ao encontro de novos
conhecimentos. O sábio é substituído pelo professor onde sua excelência se medirá pelo
acompanhamento e atualização e a nova tarefa se constitui o conteúdo do ensino. Traz à
tona que todas essas fica bem informal
do conhecimento, e faz a relação do ratio studiarium com a identidade do "capataz do
livro didático", e apresenta-nos a metáfora que o compara a uma capataz de uma fábrica
cujo objetivo seja apenas o controle através de material selecionado.

Fonte: Texto de G.S. / Arquivo pessoal dos autores 
Quadro 3 - Excerto de G.S. (versão reescrita)

O autor ainda discute sobre as identidades históricas atribuídas ao professor, a primeira como
um sábio, detentor de todo o conhecimento num momento que a educação era dominada pelo clero
e prezava pela rigidez, reprodução, o apego ao dogma e a autoridade. Fica evidente as causas da
desatualização do professor que segundo Guedes, levando-se em conta o monopólio exercido pelos
jesuítas que mantiveram uma educação fechada e irredutível na qual "o saber estava pronto e
acabado", o professor não ia além dos livros e ao encontro de novos conhecimentos, como também
existia a repugnância e o desinteresse por atividades artísticas e técnicas. Para ele, com o surgimento
do mercantilismo muda um pouco esse cenário no qual o "sábio" é substituído pelo professor e sua
excelência será medida pelo acompanhamento e atualização, a sua nova tarefa constitui-se o
conteúdo do ensino. Embora proporcionasse um pouco mais de liberdade ainda reflete a questão de
que essas identidades históricas sempre estiveram muito longe da produção do conhecimento.
Guedes faz a relação do "ratio studiarium" com a identidade do "capataz do livro didático", e
apresenta-nos a metáfora que o compara a uma capataz de uma fábrica cujo objetivo seja apenas o
controle através de material selecionado.

Fonte: Texto de G.S. / Arquivo pessoal dos autores

No excerto da versão inicial, a primeira solicitação diz respeito à alteração de um verbo que assegure mais formalidade ao texto. A substituição é bem-sucedida, pois, ao atender ao comentário, o aluno ainda escolhe um verbo que, no seu entender, melhor expressa a ação verbal do autor da obra, traduzindo também uma avaliação acerca do conteúdo temático. Mas é a segunda observação que suscita uma reflexão mais profunda e alterações mais substanciais no texto, em diferentes dimensões. O comentário incide sobre os mecanismos enunciativos, quanto ao gerenciamento das vozes do resenhista e do autor da obra, que não aparecem suficientemente delimitadas na primeira versão. Ao realizar a reescrita, o autor da resenha insere elementos para deixar claro que as ideias provêm do autor da obra resenhada, como expressões introdutoras de discurso relatado ("o autor discute", "segundo Guedes", "para ele", "Guedes faz" e elipse no verbo "apresenta"), além de trechos entre aspas que indicam inclusão da voz de outrem no texto. Nesse processo, também cria, na dimensão da textualização, uma cadeia referencial para se referir ao autor da obra resenhada através de diferentes recursos e, principalmente, procede a acréscimos no conteúdo temático, incluindo mais informações sobre a obra, o que tem impacto sobre o plano geral do texto, já que amplia a etapa do resumo.

Este último exemplo também ilustra a articulação entre as capacidades de linguagem. Vejamos: 
Figura 5 - Excerto de G.S. (primeira versão)

O professor deve assumir a tarefa de ensinar a ler e escrever literatura brasileira,
não necessariamente precisa ser um artista ou propor uma foficina de criação literária,
mas propor uma aula que leve em conta o lugar em que todos assumirão seu discurso,
olhar de perto essa prática e fazer a reflexão junto com seus alunos, ambos construindo
sua identidade, para isso é necessário a qualificação do professor e o domínio da
língua, para propiciar os diferentes usos em sala de aula.

Fonte: Texto de G.S. / Arquivo pessoal dos autores

Quadro 4 - Excerto de G. S. (versão reescrita)

\begin{abstract}
O professor deve assumir a tarefa de ensinar a ler e escrever literatura brasileira, não necessariamente precisa ser um artista ou propor uma oficina de criação literária, não se trata de instruir o aluno a contrariar o discurso colonizado ao longo do tempo pela elite, mas propor ao aluno a tarefa de "construir-se e expressar um entendimento a respeito de si mesmo, guiando-se pelo depoimento expresso na literatura brasileira por participantes da cultura e da nação de que faz parte" (p.52). A aula deve levar em conta o lugar em que todos assumirão seu discurso, olhar de perto essa prática e fazer a reflexão junto a seus alunos, ambos construindo suas identidades, mas para que isso aconteça é necessário a qualificação do professor e o domínio da língua, visando propiciar os diferentes usos do conhecimento em sala de aula.
\end{abstract}

Fonte: Texto de G.S. / Arquivo pessoal dos autores

O comentário na correção aponta para a inserção de explicações sobre um termo utilizado na obra resenhada, logo, na dimensão do conteúdo temático com implicações no plano geral. O aluno, na reescrita, busca seguir a orientação: explica o termo, ampliando a etapa textual dedicada a resumir. Ao realizar essa tarefa, introduz a intertextualidade como recurso argumentativo, fazendo uso da menção à voz do autor da obra resenhada, delimitada entre aspas. Nesse caso, há ainda implicações sobre os elementos enunciativos e a construção da sequência argumentativa. É importante destacar, porém, que o autor não emprega elementos introdutores nesse discurso relatado, nem faz qualquer outra menção no parágrafo ao autor da obra, embora reconheçamos que se trata da etapa do resumo, de modo que as ideias ali expressas não representam o ponto de vista do resenhista. Assim, apesar da utilização de um trecho da obra como recurso intertextual, o aluno demonstra dificuldade de demarcar as instâncias enunciativas responsáveis por porções do conteúdo temático, o que seria essencial para entendermos quando o resenhista está semiotizando as operações de linguagem que definem os dois grandes objetivos da resenha: resumir ou comentar a obra.

Como vemos, os aspectos mais problemáticos das resenhas, que guiam as ações do professor na correção e dos alunos na reescrita, são o conteúdo temático e sua planificação e o gerenciamento enunciativo. Esses aspectos, entretanto, permeiam todos os níveis de constituição do texto, desde os aspectos linguísticos e textuais até questões relacionadas a papéis sociais, vivências e atuação num campo disciplinar que dê aos alunos conhecimento e 
legitimidade para melhor dominar a prática de escrita em que se envolvem. Na situação aqui analisada, por exemplo, os alunos devem assumir uma condição de especialista, mas não o são deveras, o que tem repercussão nas diferentes dimensões de construção do texto, especialmente na dificuldade de dominar e planificar alguns conteúdos, na construção da argumentação, na remissão à literatura especializada, no uso de convenções acadêmicas referentes a gerenciamento de vozes. Não se trata, portanto, apenas do domínio de um modelo de gênero, mas de um processo de compreensão quanto à construção de identidade e de domínio de convenções e de conteúdos no âmbito de uma disciplina, que se materializa em elementos discursivos, textuais e linguísticos que semiotizam tal prática linguageira.

\section{Conclusão}

As reflexões aqui empreendidas evidenciam a importância de uma rotina de apresentação, exploração e vivência de especificidades do gênero, consubstanciada na perspectiva dos letramentos, ao longo da condução das atividades de produção de texto. Entendemos que as atividades com a escrita contemplam dimensões que vão além dos limites da materialidade textual, envolvem vivências e agentividade, e, ao mesmo tempo, são essas práticas sociais de que participam os graduandos que vão lhes assegurar melhores condições de apropriação do gênero, no processo de textualização. Nesse sentido, buscamos enfatizar que a noção de capacidades de linguagem - ação, discursiva e linguístico-discursiva (DOLZ, SCNHEUWLY, 2014) - tem proporcionado uma abordagem que contempla tanto os aspectos referentes aos contextos de produção dos gêneros acadêmicos, quanto os aspectos estruturais e linguístico-discursivos dos textos. Na avaliação dos textos, observamos um tal imbricamento entre as capacidades de linguagem que as operações de ajuste referentes aos aspectos sociocomunicativos do gênero, por exemplo, são viabilizadas no uso de recursos linguísticos específicos, tais como verbos, conjunções e pronomes. Entendemos, desse modo, que, no processo didático de abordagem dos gêneros, imbricam-se aspectos sociocomunicativos, discursivos e linguísticos, fazendo-se necessário contemplar situações de reflexão e revisão textuais por meio das quais o uso efetivo dos elementos da materialidade textual seja também exercitado, a fim de explicitar e abordar os diferentes elementos constitutivos do gênero. Trata-se, portanto, do encontro com novos gêneros, com convenções e com a construção de identidades e papéis sociais que demandam diversas práticas, num processo formativo constante, em que os alunos vão dominando conhecimentos tanto de conteúdos e gêneros, quanto de valores e formas de inserção no fazer acadêmico na universidade. 


\section{Referências}

ARAÚJO, J.; BARROS, M. G.; SILVA, E. S. Práticas de reescrita no ensino do gênero resenha. Rev. bras. linguist. apl., Belo Horizonte, v. 15, n. 1, p. 109-130, mar. 2015.

BALTAR, M. A competência discursiva e gêneros textuais: uma proposta pedagógica para a LPI. Trab. linguist. apl., Campinas, v. 45, n. 2, p. 175-186, dez. 2006.

BARTON, D.; HAMILTON, M. Local literacies: reading and writing in one community. Londres; Nova York: Routledge, 1998.

BARTON, D.; HAMILTON, M. Literacy practices. In: BARTON, D.; HAMILTON, M.; IVANIČ, R. (Ed.). Situated literacies: reading and writing in context. Londres; Nova York: Routledge, 2000. p. 7-14.

BRAGA, S.; SENEM, J. O aluno na posição de autor: uma experiência com a resenha na universidade. Fórum Linguístico, Florianópolis, v. 14, n. 4, p. 2685-2702, dez. 2017. https://doi.org/10.5007/1984-8412.2017v14n4p2685

BRONCKART, J.-P. Atividade de linguagem, textos e discursos: por um interacionismo sóciodiscursivo. São Paulo: Educ, 1999.

BRONCKART, J-P. Atividade de linguagem, discurso e desenvolvimento humano. Campinas: Mercado de Letras, 2006.

CAVALCANTE, R. P. Universidade de Genebra: Faculdade de Psicologia e Ciências da Educação. Revista Prolíngua, João Pessoa, v. 10, n. 3, p. 105-117, nov. 2015. Disponível em: http://bit.ly/2vJmhZA. Acesso em: 16 maio 2016.

CUNHA, G. X. A forma de organização composicional do gênero resenha acadêmica: uma análise das sequências discursivas e de suas funções. Fórum Linguístico, Florianópolis, v. 11, n. 2, p. 112-122, fev. 2014. https://doi.org/10.5007/1984-8412.2014v11n2p112

DOLZ, J.; SCHNEUWLY, B. Gêneros e progressão em expressão oral e escrita: elementos para uma reflexão sobre uma experiência suíça (francófona). In: SCHNEUWLY, B.; DOLZ, J. (Org.). Gêneros orais e escritos na escola. Campinas: Mercado de Letras, 2004. p. 41-70.

DOLZ, J.; NOVERRAZ, M.; SCHNEUWLY, B. Sequências didáticas para o oral e a escrita: apresentação de um procedimento. In: SCHNEUWLY, B.; DOLZ, J. (Org.). Gêneros orais e escritos na escola. Campinas, SP: Mercado de Letras, 2004. p. 95-128.

GEE, J. P. Social linguistics and literacies: ideology in discourses. 3. ed. Abingdon; Nova York: Routledge, 2008. https://doi.org/10.4324/9780203944806

GUEDES, P. C. A formação do professor de português: que língua vamos ensinar?. São Paulo: Parábola Editorial, 2006.

KLEIMAN, A. B. (Org.). Os significados do letramento: uma nova perspectiva sobre a prática social da escrita. Campinas: Mercado de Letras, 1995.

KLEIMAN, A. B.; ASSIS, J. A. (Org.). Significados e ressignificações do letramento: desdobramentos de uma perspectiva sociocultural sobre a escrita. Campinas: Mercado de Letras, 2016.

LEA, M. R. Academic literacies: a pedagogy for course design. Studies in Higher Education, 
New York, v. 29, n. 6, p. 739-756, Dec. 2004. Disponível em: http://bit.ly/2P6mmyB. Acesso em: 11 maio 2017. https://doi.org/10.1080/0307507042000287230

LEA, M. R. "Communities of practice" in higher education. In: BARTON, D.; TUSTING, K. (Ed.). Beyond communities of practice: language, power and social context. Cambridge: Cambridge University Press, 2005. p. 180-197.

LEA, M. R.; STREET, B. V. Student writing in higher education: an academic literacies approach. Studies in Higher Education, Nova York, v. 23, n. 2, p. 157-172, jun. 1998. Disponível em: http://bit.ly/2Patpqf. Acesso em: 14 ago. 2018. https://doi.org/10.1080/03075079812331380364

LEA, M. R.; STREET, B. V. (Ed.). Student writing in higher education: new contexts. Milton Keynes; Philadelphia: Open University Press; Society for Research into Higher Education, 2000.

LEA, M. R.; STREET, B. V. O modelo de "letramentos acadêmicos": teoria e aplicações. Revista Filologia e Linguística Portuguesa, São Paulo, v. 16, n. 2, p. 477-493, jul.-dez. 2014. Disponível em: http://bit.ly/2B5EhTb. Acesso em: 15 maio 2017.

LILLIS, T. Student Writing as 'Academic Literacies': Drawing on Bakhtin to Move from Critique to Design. Language and Education, v. 17, n. 3, p. 192-207, 2003. Acesso em: 21 fev. 2019. https://doi.org/10.1080/09500780308666848

LILLIS, T. Whose 'commom sense'?: essayist literacy and the institutional practice of mystery. In: JONES, C.; TURNER, J.; STREET. B. (Ed.). Students writing in the university: cultural and epistemological issues. Amsterdã; Filadélfia: John Benjamins Publishing Company, 1999. p. 127-147. https://doi.org/10.1075/swll.8.13lil

LOUSADA, E. G.; SANTOS, T. J. F.; BARIONI, M. C. O gênero "resenha acadêmica" no ensino de francês a alunos universitários. Gláuks, Viçosa, MG, v. 16, n. 1, p. 131-151, 2016.

MACHADO, A. R. A organização sequencial da resenha crítica. The ESPecialist, São Paulo, v. 17, n. 2, p. 133-149, 1996.

MACHADO, A. R. A perspectiva interacionista sociodiscursiva de Bronckart. In: MEURER, J. L.; BONINI, A.; MOTA-ROTH, D. (Org.). Gêneros: teorias, métodos, debates. São Paulo: Parábola Editorial, 2005. p. 237-259.

MACHADO, A. R.; LOUSADA, E.; ABREU-TARDELLI, L. S. Resenha. São Paulo: Parábola Editorial, 2004.

MOTTA-ROTH, D.; HENDGES, G. R. Produção textual na universidade. São Paulo: Parábola Editorial, 2010.

NAVARRO, F. (Coord.). Manual de escritura para carreras de Humanidades. Buenos Aires: FILO: UBA Colección Sol de Noche SN, 2014.

PEREIRA, R. C. M.; BASÍLIO, R. A didatização da resenha acadêmica em contexto universitário. In: NASCIMENTO, E. L.; ROJO, R. H. R. (Org.). Gêneros de texto/discurso e os desafios da contemporaneidade. Campinas, SP: Pontes, 2014. p. 235-256.

RODRIGUES, F. L. F. A construção da crítica em resenhas produzidas por alunos. Ling. (dis)curso, Tubarão, v. 13, n. 2, p. 273-297, ago. 2013. Acesso em: $21 \mathrm{fev}$. 2019. https://doi.org/10.1590/S1518-76322013000200004 
RUIZ, E. M. S. D.; FARIA, M. B. A intertextualidade no gênero resenha. Ling. (dis)curso, Tubarão, v. 12, n. 1, p. 99-128, abr. 2012.

https://doi.org/10.1590/S1518-76322012000100005

SCHNEUWLY, B.; DOLZ, J. Os gêneros escolares: das práticas de linguagem aos objetos de ensino. In: SCHNEUWLY, B.; DOLZ, J. (Org.). Gêneros orais e escritos na escola. Campinas, SP: Mercado de Letras, 2004. p. 71-91.

SOARES, M. Alfabetização e letramento. 4. ed. São Paulo: Contexto, 2006.

SOARES, M. Letramento: um tema em três gêneros. 3. ed. Belo Horizonte: Autêntica, 2009.

STREET, B. 'Academic literacies approaches to genre'?. Rev. bras. linguist. apl., Belo Horizonte, v. 10, n. 2, p. 347-361, 2010a. https://doi.org/10.1590/S1984$\underline{63982010000200004}$

STREET, B. Dimensões "escondidas" na escrita de artigos acadêmicos. Perspectiva, Florianópolis, v. 28, n. 2, p. 541-567, jul. 2010b. https://doi.org/10.5007/2175795X.2010v28n2p541

STREET, B. V. Literacy in theory and practice. Cambridge: Cambridge University Press, 1984.

STREET, B. V. Introduction: the new literacy studies. In: STREET, B. V. (Ed.). Cross-cultural approaches to literacy. Cambridge: Cambridge University Press, 1993. p. 1-21. Acesso em: 10 jun. 2017.

STREET, B. V. Letramentos sociais: abordagens críticas do letramento no desenvolvimento, na etnografia e na educação. São Paulo: Parábola Editorial, 2014.

SWIDERSKI, R. M. da S.; COSTA-HÜBES, T. da C. Abordagem sociointeracionista e sequência didática: relato de uma experiência. Línguas \& Letras, [S.I.], v. 10, n. 18, p. 113-128, jun. 2009.

TURNER, J. Academic literacy and the discourse of transparency. In: JONES, C.; TURNER, J.; STREET. B. (Ed.). Students writing in the university: cultural and epistemological issues. Amsterdã; Filadélfia: John Benjamins Publishing Company, 1999. p. 149-160. https://doi.org/10.1075/swll.8.14tur

Recebido em: 08/03/2019

Aceito em: 04/07/2019 